(C) Österreichische Apotheker-Verlagsgesellschaft m. b. H, Wien, Printed in Austria

\title{
Seasonal Depending Variations of the Composition and Biological Activities of Douglas Fir (Pseudotsuga menziesii) Essential Oils from Bulgaria
}

\author{
Leopold Jirovetz* and Gerhard Buchbauer \\ Institute of Pharmaceutical Chemistry, University of Vienna \\ Althanstrasse 14, A-1090 Vienna, Austria
}

Albena Stoyanova and Stoyan Metodiev

Higher Institute of Food and Flavour Industries, Department of Essential Oils, Maritza 26, 4002 Plovdiv, Bulgaria

The seasonal depending variations of the essential oils of the needles with twigs of Bulgarian Douglas fir (Pseudotsuga menziesii, Pinaceae) were analyzed by GC-FID, GC-MS and olfactoric evaluation. In totally 8 investigated essential $P$. menziesii oils about 60 compounds could be identified with monoterpenes (especially sabinene and $\beta$-pinene) as main constituents. The antimicrobial effects against bacteria, fungi and worms of these volatiles as well as their olfactoric properties will be discussed.

Keywords: Pseudotsuga menziesii, Pinaceae, essential oil of the needles with twigs, GC-FID, GC-MS, antimicrobial activity

\section{Introduction}

Douglas fir (Pseudotsuga menziesii Mirb. Franco) is a well-known and widespread Pinaceae species in Europe and America. Beside the use of the essential $P$. menziesii oils of the needles, the twigs and the bark in various fields of cosmetics and perfumery also some studies [1-5] of antimicrobial activities against bacteria, fungi and worms have been published.

In our investigation the seasonal depending variation of the essential oil composition using GC-FID, GC-MS and olfactometry as well as of the biological effects using antimicrobial testings will be discussed.

\section{Results and discussion}

From June 1999 to February 2000 in total 8 samples of Douglas fir (Pseudotsuga menziesii Mirb. Franco, Pinaceae) essential oils of needles with twigs from Bulgaria were obtained by steam distillation and the volatiles investigated by GCFID, GC-MS, olfactometry and antimicrobial testings to get information about the qualitative and quantitative composition as well as the biological activities of the single oils. 
The olfactoric evaluation of the samples showed that the significant fresh fir odor with pinenes, citronellal, citronellol and teatree-oil notes has been found in all oils with only lightly different intensities.

Using gas chromatographic-spectroscopic methods (GC-FID and GC-MS) with columns of different polarities more than 80 volatiles could be detected and about 60 of them identified as Douglas fir essential oil constituents (see Table 1).

Table 1. Composition of the Douglas fir essential oils of fresh needles and twigs from Bulgaria (Identification by mass spectra, retention-index and olfactoric correlations in accordance to [6-9]).

\begin{tabular}{|c|c|c|c|c|c|c|c|c|c|}
\hline Compound $^{\mathrm{a}}$ & 1 & 2 & 3 & 4 & 5 & 6 & 7 & 8 & $\mathrm{RI}^{\mathrm{b}}$ \\
\hline cis-3-hexen-1-ol & 2.7 & 1.3 & 0.9 & 0.7 & 0.6 & 0.6 & 0.3 & 0.5 & 841 \\
\hline hexanol & 1.5 & 1.5 & 1.3 & 1.4 & 1.2 & 0.9 & 0.5 & 0.4 & 849 \\
\hline$\alpha$-thujene & 0.7 & 0.1 & 0.3 & 0.8 & 0.5 & 0.3 & 0.4 & 0.7 & 935 \\
\hline$\alpha$-pinene & 8.9 & 6.5 & 6.1 & 6.8 & 7.9 & 5.1 & 5.3 & 4.4 & 944 \\
\hline heptanol & 0.4 & 0.2 & 0.1 & 0.4 & 0.5 & 0.2 & 0.4 & 0.5 & 952 \\
\hline camphene & 0.3 & 0.4 & 0.6 & 0.9 & 1.1 & 1.2 & 1.4 & 1.3 & 954 \\
\hline cis-3-hexenyl acetate & 1.3 & 0.7 & 0.6 & 0.4 & 0.2 & 0.3 & 0.1 & 0.3 & 972 \\
\hline sabinene & 16.7 & 14.9 & 16.9 & 13.9 & 13.2 & 14.7 & 14.4 & 15.4 & 974 \\
\hline$\beta$-pinene & 22.0 & 20.8 & 14.7 & 19.8 & 25.9 & 16.3 & 15.9 & 14.2 & 978 \\
\hline$\beta$-myrcene & 2.3 & 1.7 & 1.2 & 1.5 & 1.2 & 0.9 & 1.6 & 1.2 & 991 \\
\hline$\alpha$-phellandrene & 0.8 & 1.3 & 0.8 & 1.6 & 0.8 & 2.1 & 1.8 & 1.3 & 1007 \\
\hline 1,4-cineole & $\mathrm{tr}^{\mathrm{c}}$ & tr & 0.1 & 0.1 & 0.2 & 0.3 & 0.2 & 0.1 & 1009 \\
\hline$\alpha$-terpinene & 2.1 & 4.4 & 3.7 & 1.8 & 2.1 & 2.2 & 1.9 & 2.1 & 1016 \\
\hline p-cymene & 0.6 & 0.4 & 0.9 & 1.4 & 0.9 & 1.3 & 1.4 & 0.9 & 1019 \\
\hline 1,8-cineole & 0.2 & 0.5 & 0.7 & 0.9 & 1.0 & 0.7 & 0.9 & 0.4 & 1021 \\
\hline limonene & 1.2 & 1.1 & 1.6 & 1.4 & 0.7 & 0.3 & 0.5 & 0.2 & 1025 \\
\hline cis- $\beta$-ocimene & 0.1 & 0.3 & 1.0 & 1.2 & 1.1 & 1.7 & 1.0 & 1.8 & 1028 \\
\hline$\beta$-phellandrene & 2.5 & 0.6 & 3.7 & 3.2 & 4.2 & 3.2 & 3.0 & 3.1 & 1031 \\
\hline trans- $\beta$-ocimene & 0.2 & 0.4 & 0.6 & 0.5 & 0.7 & 1.1 & 1.3 & 1.5 & 1040 \\
\hline$\gamma$-terpinene & 2.3 & 4.4 & 2.8 & 3.2 & 4.1 & 5.3 & 5.2 & 5.7 & 1057 \\
\hline dihydro-myrcenol & $\mathrm{nd}^{\mathrm{d}}$ & tr & $\operatorname{tr}$ & 0.1 & 0.1 & $\operatorname{tr}$ & nd & $\mathrm{tr}$ & 1064 \\
\hline$\alpha$-terpinolene & 6.4 & 11.8 & 13.1 & 11.3 & 11.7 & 15.0 & 16.2 & 16.1 & 1077 \\
\hline linalool & 0.5 & 0.6 & 0.7 & 0.7 & 0.6 & 1.1 & 1.3 & 1.6 & 1096 \\
\hline myrcenol & tr & tr & 0.1 & 0.2 & $\operatorname{tr}$ & $\mathrm{tr}$ & $\mathrm{tr}$ & nd & 1103 \\
\hline phenylethanol & nd & tr & 0.2 & 0.3 & nd & 0.2 & 0.6 & 0.5 & 1105 \\
\hline$\beta$-pinene oxide & tr & 0.1 & 0.4 & 0.8 & 1.2 & 1.4 & 1.5 & 1.7 & 1109 \\
\hline fenchol & nd & tr & 0.1 & 0.2 & $\mathrm{tr}$ & 0.2 & $\mathrm{tr}$ & nd & 1116 \\
\hline isopulegol & nd & nd & tr & 0.1 & 0.1 & $\mathrm{tr}$ & nd & 0.1 & 1129 \\
\hline camphor & 0.1 & 0.2 & 0.3 & 0.5 & 0.2 & 0.3 & 0.4 & 0.3 & 1132 \\
\hline trans-pinocarveol & $t r$ & 0.1 & 0.2 & 0.3 & $\operatorname{tr}$ & tr & 0.1 & nd & 1135 \\
\hline citronellal & 3.0 & 0.4 & 1.2 & 0.9 & 1.6 & 1.2 & 1.9 & 1.8 & 1139 \\
\hline trans-verbenol & nd & tr & 0.1 & 0.2 & tr & 0.1 & nd & 0.1 & 1141 \\
\hline borneol & tr & tr & 0.1 & 0.1 & 0.2 & tr & nd & 0.2 & 1163 \\
\hline p-cymen-8-ol & nd & tr & tr & 0.1 & 0.1 & nd & nd & nd & 1168 \\
\hline terpinen-4-ol & 6.9 & 9.6 & 5.2 & 3.8 & 3.1 & 7.3 & 7.4 & 8.7 & 1182 \\
\hline$\alpha$-terpineol & 5.1 & 2.5 & 2.4 & 1.5 & 1.0 & 1.3 & 0.9 & 1.5 & 1186 \\
\hline dihydrocarveol & $\operatorname{tr}$ & tr & 0.1 & 0.2 & tr & nd & $\operatorname{tr}$ & nd & 1190 \\
\hline octyl acetate & $\operatorname{tr}$ & $\operatorname{tr}$ & tr & 0.1 & nd & nd & nd & nd & 1194 \\
\hline B-cyclocitral & 0.4 & 0.3 & 0.4 & 0.6 & 0.2 & $\operatorname{tr}$ & 0.3 & 0.2 & 1201 \\
\hline citronellol & 1.3 & 1.8 & 3.2 & 2.8 & 2.3 & 3.9 & 3.4 & 3.3 & 1217 \\
\hline carvone & $\mathrm{tr}$ & $\operatorname{tr}$ & 0.1 & 0.1 & nd & $\mathrm{tr}$ & tr & nd & 1227 \\
\hline geraniol & 0.1 & 0.4 & 0.9 & 1.1 & 0.3 & 0.5 & 0.6 & 0.5 & 1238 \\
\hline isopulegyl acetate & $\operatorname{tr}$ & tr & 0.1 & 0.1 & nd & $\operatorname{tr}$ & nd & nd & 1259 \\
\hline thymol & nd & tr & tr & 0.1 & nd & 0.1 & tr & nd & 1271 \\
\hline bornyl acetate & nd & $\mathrm{tr}$ & tr & 0.1 & nd & tr & 0.2 & nd & 1278 \\
\hline citronellyl acetate & 3.4 & 1.5 & 3.5 & 3.9 & 3.6 & 4.8 & 3.3 & 4.2 & 1334 \\
\hline
\end{tabular}




\begin{tabular}{|c|c|c|c|c|}
\hline$\alpha$-longipinene & nd & $\operatorname{tr}$ & 0.1 & 0.2 \\
\hline geranyl acetate & tr & nd & 0.2 & 0.1 \\
\hline$\alpha$-cubebene & nd & $\mathrm{tr}$ & 0.2 & tr \\
\hline$\alpha$-copaene & nd & nd & 0.1 & 0.2 \\
\hline decyl acetate & nd & nd & $\operatorname{tr}$ & tr \\
\hline$\beta$-elemene & $\mathrm{tr}$ & 0.1 & 0.5 & 0.2 \\
\hline$\beta$-caryophyllene & 0.5 & 0.7 & 0.9 & 0.7 \\
\hline trans- $\beta$-farnesene & 0.2 & 0.5 & 0.7 & 0.4 \\
\hline$\alpha$-humulene & $\mathrm{tr}$ & 0.1 & 0.2 & 0.1 \\
\hline germacrene D & $\mathrm{tr}$ & $\mathrm{tr}$ & $\mathrm{tr}$ & 0.1 \\
\hline$\alpha$-muurolene & $\mathrm{tr}$ & $\mathrm{tr}$ & $\operatorname{tr}$ & 0.2 \\
\hline$\delta$-cadinene & 0.2 & 0.4 & 0.7 & 0.8 \\
\hline caryophyllene oxide I & $\operatorname{tr}$ & $\operatorname{tr}$ & 0.1 & 0.2 \\
\hline$\delta$-cadinol & 0.1 & 0.4 & 0.3 & 0.2 \\
\hline
\end{tabular}

As main compounds of the 8 P.menziesii essential oil samples the monoterpenes $\beta$-pinene, sabinene, $\alpha$-pinene, $\alpha$-terpinolene, terpinen-4-ol, citronellal, citronellol, citronellyl acetate, $\beta$-phellandrene and $\gamma$-terpinene, only with changes in their concentration of each sample, were identified.

The correlation of the olfactoric data with gas chromatographic spectroscopic data ones allow the conclusion that the significant Douglas fir odor impressions is especially determined by $\beta$-pinene, sabinene and $\alpha$-pinene, the citronellal and citronellol notes by these monoterpenes and the teatree oil notes by terpinen-4-ol, $\alpha$-terpineol, $\alpha$-terpinolene and linalool. The change of the odor notes intensities are directly depending on the variation of the concentrations of the above mentioned monoterpenes.

Using biological testings on different microorganisms (see experimental part) the antimicrobial activity of the 8 P.menziesii essential oil samples was investigated. Significant differences in the inhibition of bacteria growth by some Douglas fir essential oils were found (see Table 2).

Table 2: Antimicrobial activieties of Pseudotsuga menziesii essential oils (needles with twigs) from Bulgaria (+++ strong effects, >25mm; ++ medium effects, $1025 \mathrm{~mm} ;+$ weak effects, to $15 \mathrm{~mm} ; 0$ no effects)

\begin{tabular}{|c|c|c|c|c|c|c|c|c|}
\hline Microorganism & $1^{*}$ & 2 & 3 & 4 & 5 & 6 & 7 & 8 \\
\hline Pseudomonas aeruginosa & + & + & + & + & + & + & + & + \\
\hline Proteus vulgaris & ++ & ++ & ++ & ++ & 0 & 0 & $+1+$ & +++ \\
\hline Serratia marcescens & + & + & + & + & 0 & + & ++ & + \\
\hline Bacillus subtilis & 0 & ++ & ++ & 0 & ++ & ++ & ++ & ++ \\
\hline Bacillus cereus & 0 & ++ & ++ & + & + & ++ & ++ & + \\
\hline Staphyllococcus aureus & + & + & + & + & + & + & + & + \\
\hline
\end{tabular}

*number of essential oil sample (see experimental part) 
In general it was found that the used Douglas fir essential oils have shown the highest activity against Proteus vulgaris, Bacillus cereus and Bacillus subtilis.

By correlation of the microbiological data with the identified main constituents of the single oil samples it is significant that terpinen-4-ol, $\alpha$-terpinolene, $\gamma$ terpinene and $\alpha$-terpinene rich Douglas fir samples (samples 2, 3, 6, 7 and 8) have stronger effects against the most tested microorganisms.

In conclusion we can report, that the seasonal depending variation of the composition of Pseudotsuga menziesii essential oils (needles and twigs) from Bulgaria has significant influences on the odor impression as well as the antimicrobial activity. The strongest effects of Douglas fir oil against microorganisms have been found in testings with Proteus vulgaris, Bacillus subtilis and Bacillus cereus. The P. menziesii essential oils with high concentrations of the monoterpenes terpinen-4-ol, $\alpha$-terpinolene, $\gamma$-terpinene and $\alpha$-terpinene show more antimicrobial activities.

\section{Experimental}

Plant material and isolation of the essential oil:

The raw material was gathered in June 1999 (sample 1), August 1999 (2), September 1999 (3), October 1999 (4), November 1999 (5), December 1999 (6), January 2000 (7) and February 2000 (8) in the region of Kazanlik at the Balkan Mountains. The essential oils were obtained by steam distillation of the fresh plant parts in a tinned copper laboratory apparatus of $5 \mathrm{dm}^{3}$ for 2 hours. The steam distillation was carried out at the rate of $10 \%$ and atmospheric pressure of the steam $(0.1 \mathrm{Mpa})$. The dynamic of the primary oil distillation was determined by measuring the oil yield every $30 \mathrm{~min}$. The procedure was stopped when no more oil could be collected in the receiver in a $30 \mathrm{~min}$ time period. The yields of essential oils are as follows: Sample 1: $0.65 \%, 2: 0.80 \%, 3: 0.64 \%, 4: 0.73 \%, 5$ : $0.82 \%, 6: 0.74 \%, 7: 0.77 \%$ and $8: 0.79 \%$.

Olfactoric evaluation of the essential oils:

200 microlitre of the essential oil (diluted with dichloromethane) was placed on a commercial odor strip (Dragoco Co.) and the odor evaluated after 10 seconds (solvent evaporation) by professional perfumers. Only minor variations of the odor impressions were found.

Instrumentation:

The volatiles of the totally 8 essential oil samples of Bulgarian Douglas fir were analyzed first by GC (Shimadzu 14A resp. Varian-3700) with FID and integrator 
systems (Shimadzu C-R6A-Chromatopac resp. Shimadzu C-R1B-Chromatopac). Carrier gas: hydrogen; injector-temperature: $250^{\circ} \mathrm{C}$; detector-temperature: $320^{\circ} \mathrm{C}$; temp.-program: $40^{\circ} \mathrm{C} / 5 \mathrm{~min}$. to $280^{\circ} \mathrm{C} / 10 \mathrm{~min}$. with heating-rate of $8^{\circ} \mathrm{C} / \mathrm{min}$; columns: $30 \mathrm{~m} \times 0.32 \mathrm{~mm}$ bonded FSOT-RSL-200 fused silica (film thickness: 0.25 micron; Biorad Co.); quantification by \%-peak-area-calculation; compound identification partly by co-injection of pure compounds and retention-time correlations in accordance with [6-9].

The second used hyphenated system was GC-MS (Shimadzu GC-17A with QP5000 and datasystem Compaq-ProLinea with Class5k-software resp. HewlettPackard GC-HP5890 with HP5970-MSD and datasystem PC-Pentium (Böhm Co.) with HPCHEM-software). Carrier gas: helium; injector-temperature: $250^{\circ} \mathrm{C}$; interface-heating: $300^{\circ} \mathrm{C}$; ion-source-heating: $200^{\circ} \mathrm{C}$; El-mode; $70 \mathrm{eV}$; scanrange: 41-450 amu; temp.-program and column see GC-FID part. Mass spectra correlations with Wiley-, NBS- and NIST-library spectra on-line resp. in accordance to [9] off-line.

Microbiological testings:

The antibacterial activity was studied using the Agar-Diffusion-Cup-Method: cups [3,4]: $0.6 \mathrm{~cm}$ and volume: $0.01 \mathrm{ml}$ for each product. The following microorganisms were used: Pseudomonas aeruginosa, Proteus vulgaris, Serratia marcescens, Bacillus subtilis, Bacillus cereus and Staphylococcus aureus.

\section{Acknowledgments}

We acknowledge the olfactoric evaluation of the sample by Mr. W. Höppner and Mr. V. Hausmann, chief-perfumers of Dragoco Co., Vienna-Austria.

\section{REFERENCES}

[1] Buchbauer, G., Jirovetz, L., Wasicky, M., Nikiforov, A. (1994), J.Agric. Food Chem. 42:2852.

[2] Chalchat, J.C., Garry, R.Ph., Bastide, P., Fabre, F., Malhuret, R. (1991), Plant.Med.Phytother. 25: 184 .

[3] Stojanova, A., Metodiev, S., Karova, E., Posterpresentation (no. MM67) at the First Balcan Conference of Microbiology „Microbiologia Balkanica '99), Plovdiv (Bulgaria), October 5-9, 1999.

[4] Zaika, L. (1988), Food Safety 9:97.

[5] Yonov, N. (1992), Sci.Woods 4:69.

[6] Davies, N.W. (1990), J.Chromatogr. 503:1.

[7] Jennings, W., Shibamoto, T. (1980). Qualitative Analysis of Flavor and Fragrance Volatiles by Glass Capillary Gas Chromatography, Academic Press, New York. 
[8] Private Retention-time tables of flavor and fragrance compounds.

[9] Schmaus, G. (1988). Thesis: Untersuchungen über die Zusammensetzung der ätherischen Wurzelöle verschiedener mittel- und westeuropäischer Peucedanum-Arten (Apiaceae) unter besonderer Berücksichtigung von Peucedanum palustre (L.) Moench und Peucedanum lancifolium Lange, University of Würzburg, Germany. 